\title{
Evaluation of enzyme-linked immunosorbent assay using crude Leishmania and recombinant antigens as a diagnostic marker for canine visceral leishmaniasis
}

\author{
Eliza Yoshie do Rosário, 0 dair Genaro ${ }^{\dagger}$, João C França-Silva, Roberto T da Costa, \\ Wilson Mayrink, Alexandre Barbosa Reis*, Mariângela Carneiro/ ${ }^{+}$
}

Departamento de Parasitologia, Instituto de Ciências Biológicas, Universidade Federal de Minas Gerais, Av. Antonio Carlos 6627, 31270-901 Belo Horizonte, MG, Brasil *Laboratório de Parasitologia e Histopatologia, Núcleo de Pesquisas de Ciências Biológicas, Universidade Federal de Ouro Preto, Ouro Preto, MG, Brasil

The performances of ELISA assays with different antigen preparations, such as Leishmania amazonensis or $\mathrm{L}$. chagasi lysates and the recombinant antigens $r K-39$ and $r K-26$, were compared using sera or eluates from dried blood collected on filter paper to detect anti-Leishmania antibodies in dogs from a visceral leishmaniasis-endemic area in Brazil. Of 115 IFAT-reactive dogs at 1:40 titre, 106 (92.2\%) were positive in parasitological exams (skin and/or spleen). These animals were compared to healthy animals $(n=25)$, negative for IFAT at a titre of 1:40 and parasitological exams. The sensitivities of crude and recombinant antigens were similar and remarkably high for both sera and eluates (97-100\%). Specificity was higher than 96\% for sera and eluates for different antigens, except for L. chagasi antigen using eluates (88\%). Concordance values among the tests were higher either for sera or eluates $(J=0.95-1.00)$. High concordances were observed between sera and eluates tested with different antigens (kappa $=0.93-0.97)$. Crude and recombinant antigens identified different clinical phases of canine leishmaniasis. These results show that eluates could be used in canine surveys to identify L. chagasi infection. Recombinant antigens added little when compared to crude antigen in identifying positive dogs. Cross-reactivity with other diseases whose distribution often overlaps VL-endemic areas is a limitation of crude antigen use however.

Key words: canine visceral leishmaniasis - Leishmania (Leishmania) chagasi - diagnosis - recombinant antigens

Visceral leishmaniasis (VL) is a zoonosis caused by Leishmania (Leishmania) chagasi and transmitted by the phlebotomine sand fly Lutzomyia (Lutzomyia) longipalpis in Brazil. VL occurs in both rural and urban areas and has become a serious public health problem in several large Brazilian cities in recent decades (Arias et al. 1996). Domestic dogs play an important role in VL maintenance in man-made environments by serving as reservoirs of the parasite (Deane \& Deane 1962). In Brazil, canine visceral leishmanisis (CVL) prevalence ranges from 1.9 to $35 \%$ in endemic areas (Evans et al. 1990, Nunes et al. 1991, FrançaSilva et al. 2002). The parasite can be isolated by means of tissue biopsies in 40-50\% of dogs with positive immunofluorescence titres (Lanotte et al. 1979, Pozio et al. 1981) as well as asymptomatic animals (Marzochi et al. 1985). Consequently, asymptomatic and symptomatic infected dogs are both infective to the sand fly vectors (Molina et al. 1994).

Recommended VL control strategies in Brazil involve systematic treatment of human cases, elimination of seropositive dogs and residual spraying of houses and animal shelters with insecticides (Vieira \& Coelho 1998). Due to the difficulty of direct detection of the parasite and the

\footnotetext{
${ }^{+}$Corresponding author. E-mail: mcarneir@icb.ufmg.br

† Deceased in 8 March 2002

Received 30 August 2004

Accepted 7 March 2005
}

high proportion of asymptomatic dogs, serological methods are essential for CVL diagnosis. Although the immunofluorescent antibody test (IFAT) is the most widespread diagnostic method, cross-reactivity with other diseases and low sensitivity in detecting asymptomatic dogs are the main limitations of this technique. In addition, IFAT is not readily adaptable to large-scale seroepidemiological studies (Mancianti et al. 1995). The enzyme-linked immunosorbent assay (ELISA) has proved to be at least as sensitive and specific as IFAT and is suitable for such surveys (Evans et al. 1990, Paranhos-Silva et al. 1996, Braga et al. 1998). Cross-reactivity with other canine parasites and bacterial pathogens has also been reported for ELISA (Roffi et al. 1980, Mancianti et al. 1996). Crude antigen preparations made from whole promastigotes or their soluble extracts limit standardization of the tests and reproducibility of the results (Hommel et al. 1978, Mohammed et al.1986, Burns et al. 1993). Recombinant antigens have been developed and tested using ELISA to identify active subclinical and asymptomatic leishmaniasis (Badaró et al. 1996, Braz et al. 2002, Carvalho et al. 2003). These include the recombinant antigens $\mathrm{rK}-39$ and $\mathrm{rK}-26$ from $L$. chagasi, which have shown high sensitivity and specificity in CVL serodiagnosis (Burns et al. 1993, Bhatia et al. 1999, Scalone et al. 2002).

In Brazil, seroepidemiological canine surveys have been conducted using filter paper to collect blood for serological tests. The Brazilian Ministry of Health recently recommended the substitution of the serology using eluates from dried blood collected on filter paper with conventional serology using serum samples (Costa \& Vieira 2001). 
This is mainly because of the lower sensitivity of IFAT using eluates compared with sera in CVL diagnosis (Evans et al. 1990, Braga et al. 1998). However, some studies have shown similar results for IFAT using eluates and sera for CVL (Coutinho et al. 1985) and with ELISA for human VL (Gomes et al. 2001).

The aim of the present study was to compare ELISA using lysates of L. amazonensis and L. chagasi promastigotes and the recombinant antigens rK-39 and rK26 , performed with either sera and eluates to detect antiLeishmania antibodies in dogs from a VL-endemic area of Minas Gerais, Brazil.

\section{METHODS}

Dogs and blood sample collection - In the present study ELISA performed on sera was compared with that using eluates from blood dried on filter paper from 140 dogs. These were made up of 115 dogs reactive for IFAT at a titer of 1:40, identified in a field survey conducted in Janaúba, MG and 25 healthy animals obtained from the kennels of the UFMG Parasitology Department, IFAT-negative at 1:40. In addition a further 101 serum samples were also tested, including 27 from negative healthy dogs kept in the Leishmaniasis Laboratory of the UFMG Parasitology Department and 74 from dogs infected with other pathogens (40 with Trypanosoma cruzi, 24 with Babesia canis and 10 with Dirofilaria immitis).

Blood samples were collected by venipuncture from the jugular radial vein. A drop of blood was spread immediately onto Klabin no. 125 absorbent filter paper $(15 \times 6$ $\mathrm{cm})$. The filter papers were dried at room temperature, placed in plastic bags with silica gel to control humidity, labeled and stored at $-20^{\circ} \mathrm{C}$. The remaining blood was centrifuged and stored in aliquots at $-20^{\circ} \mathrm{C}$.

Clinical and parasitological examinations - The dogs were clinically classified based on presence/absence of signs of infection as being asymptomatic, oligoasymptomatic and symptomatic, as described by Mancianti et al. (1988). Euthanasia of the 115 dogs from Janaúba reactive for $L$. chagasi was performed according to the standard operating practices of the National Health Foundation, Ministry of Health in the Diseases Control Centre of Montes Claros. Necropsies were performed and tissue fragments from the skin at the border of the ears and from the spleen were collected for parasitological examinations. Skin fragments from the ears were also collected from the 25 healthy dogs. The fragments were smeared onto slides, stained with Giemsa and examined under optical microscopy to identify Leishmania amastigotes.

Serological assessment - ELISA test was performed for the $\mathrm{IgG}$ assessment against whole parasite extracts and for r-K39 and r-K26. Promastigotes of L. amazonensis (MHOM/BR/1960/BH6) and L. chagasi (MHOM/BR/1070/ BH46) were harvested from LIT (Liver Infusion Tryptose) cultures in stationary phase. The parasites were washed three times by centrifugation at $2000 \mathrm{rpm}$ in phosphate buffer solution (PBS) at $\mathrm{pH} 7.2$, for $10 \mathrm{~min}$. This was followed by three cycles of $1 \mathrm{~min}$ at $40 \mathrm{~W}$ in an ice bath in ultra-sound (Sonifer Cell Disruptor ${ }^{\circledR}$ - Branson Sonic Power Co, US). Sonicated culture material was then cen- trifuged at $18,500 \mathrm{rpm}$ for $90 \mathrm{~min}$ at $4{ }^{\circ} \mathrm{C}$. The supernatant was transferred to dialysis tubes and dialyzed through PBS for $36 \mathrm{~h}$, involving four PBS changes every $6 \mathrm{~h}$. Finally, the remaining material was filtered in disposable sterile $22 \mu \mathrm{m}$ filters under aseptic conditions and a single aliquot removed for calculation of protein dosage, after being adjusted to a concentration of $1 \mathrm{mg} / \mathrm{ml}$ and stored at $-70^{\circ} \mathrm{C}$ until use.

The antigens rK-39 and rK-26 were prepared according to the procedures described by Burns et al. (1993) and Bhatia et al. (1999) and provided by Heska Corporation, US.

A canine anti-IgG peroxidase conjugate (Sigma Co., US) was used for the ELISA tests. Reactions were read at $492 \mathrm{~nm}$. The cut-off value was established as the mean absorbancy value $+2 \mathrm{SD}$ from 52 known negative sera as well as 25 eluates from blood dried on filter paper of dogs whose sera was negative at a titre of 1:80. In order to perform the reactions, sera and filter paper were thawed and $5 \mu \mathrm{m}$ diameter spots eluted in casein-PBS for testing by ELISA.

Test reproducibility - Twenty to $30 \%$ of the samples of sera and filter paper were randomly selected in order to evaluate test reproducibility. Each duplicate received a different number from the original sample and the assays were performed blind.

Statistical Analysis - Sensitivity and specificity for ELISA performed with different antigens were compared with parasitological examinations (gold standard) using a $2 \times 2$ table. The agreements among these comparisons were expressed by Youlden index (Szklo \& Nieto 2000). Comparisons among the reactions performed with sera and eluates for each antigen and the reliability for the duplicates were evaluated by Kappa statistics (Szklo \& Nieto 2000). Absorbance values between sera and eluates for each antigen were compared by Pearson correlation. A one-way ANOVA test was used to compare the mean absorbancy values of sera and eluates for different clinical forms.

\section{RESULTS}

Sensitivity and specificity - Of 115 IFAT-reactive dogs from Janaúba, $106(92.2 \%)$ were positive in parasitological exams (skin and/or spleen) and considered to be truly positive. The 25 healthy dogs that gave negative results in parasitological exams were considered to be truly negative. A total of 131 dogs was included in sensitivity and specificity analyses.

Sensitivity and specificity of the tests are presented in Table I, together with Youlden index values. The results showed high sensitivity and specificity for ELISA performed with sera and eluates for the different antigens assayed. ELISA performed with eluates and rK39 showed the lowest sensitivity $(97.2 \%)$ while that performed with eluate and $L$. chagasi antigen presented the lowest specificity $(88 \%)$. The results showed good agreement, kappa values ranging from 0.88-1.0. The lowest concordance was observed for $L$. chagasi antigen in ELISA performed with eluate. 
TABLE I

Sensitivity, specificity and Youlden coefficient (J) of ELISA performed with crude antigens and the recombinant antigens rK-39 and rK-26 in sera and eluates in diagnosis of canine visceral leishmaniasis

\begin{tabular}{llcrr}
\hline Antigens & $\mathrm{N}=131$ & $\begin{array}{c}\text { Sensitivity \% } \\
(95 \% \mathrm{CI})\end{array}$ & $\begin{array}{c}\text { Specificity \% } \\
(\mathrm{IC} 95 \%)\end{array}$ & $\begin{array}{c}\text { Youlden } \\
(95 \% \mathrm{CI})\end{array}$ \\
\hline L. amazonensis & Sera & $100(95.6-100.0)$ & $100(83.4-100.0)$ & $1.00(1.00-1.00)$ \\
L. amazonensis & Eluate & $100(95.5-100.0)$ & $96(77.7-99.8)$ & $0.96(0.88-1.00)$ \\
L. chagasi & Sera & $98(92.7-99.7)$ & $100(83.4-100.0)$ & $0.98(0.95-1.00)$ \\
L. chagasi & Eluate & $100(95.6-100.0)$ & $88(67.7-96.8)$ & $0.88(0.75-1.00)$ \\
rK-39 & Sera & $98.1(92.7-99.7)$ & $100(83.4-100.0)$ & $0,98(0.95-1.00)$ \\
rK-39 & Eluate & $97.2(91.3-99.3)$ & $100(83.4-100.0)$ & $0,97(0.94-1.00)$ \\
rK-26 & Sera & $99.1(94.1-100.0)$ & $96(77.7-99.8)$ & $0.95(0.87-1.00)$ \\
rK-26 & Eluate & $100(95.6-100.0)$ & $96(77.7-99.8)$ & $0.96(0.88-1.00)$ \\
\hline
\end{tabular}

The results of sensitivity, specificity and Youlden coefficients were estimated with a 95\% confidence interval; L: Leishmania

Cross-reactivity analyses - Cross-reactivity was analyzed for 74 sera of different parasitic diseases. The ELISA performed with $L$. amazonensis antigen showed crossreactivity with $T$. cruzi $(25 / 40)$ and $D$. immitis (6/10). ELISA performed with $L$. chagasi were reactive with sera of $T$. cruzi (34/40), D. immitis (4/10) and B. canis (1/24). The recombinant antigens $\mathrm{rK}-39$ and $\mathrm{rK}-26$ did not show any cross-reactivity with other parasitic diseases.

Comparison among serological results and clinical form - Clinical features allowed the 115 animals to be separated into three groups. The first one was composed of 48 $(41.7 \%)$ asymptomatic dogs. The second consisted of 46 $(40 \%)$ oligosymptomatic dogs, each with a maximum of three clinical signs (opaque bristles, localized alopecia, and moderate weight loss). The third group was composed of $21(18.3 \%)$ symptomatic dogs with characteristic clinical signs of VL, such as opaque bristles, severe weight loss, onychogriphosis, cutaneous lesions, apathy, and keratoconjunctivitis.

Comparisons among the mean absorbancy values of sera and eluates for different clinical forms were performed by ANOVA. The differences between the mean absorbancy values of the three clinical phases for the four antigens assayed were not statistically significant $(\mathrm{p}>0.05)$.
The ELISA values for the different antigen preparations for sera and eluate applied to detect the clinical phases are shown in Table II. Crude antigens of $L$. amazonensis and L. chagasi detected the majority of the infected dogs, irrespective of the clinical phase, for both sera and eluate samples. The recombinant antigens were more sensitive in detecting symptomatic dogs, independent whether sera or eluate samples were used. However, no statistically significant difference was observed between the two types of antigen in this respect $(\mathrm{p}>0.05)$.

Comparisons between sera and eluates - These comparisons were performed using 140 dogs, of which 115 were IFAT-positive and 25 healthy. Among the 115 IFATpositive dogs the ELISA test performed with different antigens in sera identified 114 dogs (91.2\%) with $L$. amazonensis, $112(89.6 \%)$ with L. chagasi, 110 (88.0\%) for rK-39 and $113(90.4 \%)$ for rK-26. Concordances between sera and eluates for different antigens are shown in Table III: L. amazonensis $(\mathrm{Kappa}=0.95)$, L. chagasi $(\mathrm{Kappa}=$ 0.85), rK-39 (Kappa =0.97), and rK-26 $($ Kappa $=0.93)$.

Correlations for absorbancy values between sera and eluate using each antigen were estimated by Pearson correlation. The absorbance results were transformed to log absorbance +1 . The Pearson correlations for the different

TABLE II

Comparison between clinical phases and ELISA performed with crude antigens of Leishmania amazonensis and L. chagasi and the recombinant antigens rK-39 and rK-26 in sera and eluates

\begin{tabular}{|c|c|c|c|c|c|c|c|c|}
\hline \multirow[b]{3}{*}{ Clinical phases } & \multicolumn{8}{|c|}{ ELISA test } \\
\hline & \multicolumn{2}{|c|}{ L. amazonensis } & \multicolumn{2}{|c|}{ L. chagasi } & \multicolumn{2}{|c|}{ rK-39 } & \multicolumn{2}{|c|}{ rK-26 } \\
\hline & Sero $(\%)$ & Eluate $(\%)$ & Sero $(\%)$ & Eluate (\%) & Sero $(\%)$ & Eluate (\%) & Sero $(\%)$ & Eluate $(\%)$ \\
\hline $\begin{array}{l}\text { Asymptomatic } \\
(\mathrm{n}=48)\end{array}$ & 100 & 100 & 98 & 100 & 93.7 & 93.7 & 98 & 100 \\
\hline $\begin{array}{l}\text { Oligoasymtomatic } \\
(\mathrm{n}=46)\end{array}$ & 97.8 & 100 & 97.8 & 100 & 95.6 & 95.6 & 97.8 & 95.6 \\
\hline $\begin{array}{l}\text { Symptomatic } \\
(\mathrm{n}=21)\end{array}$ & 100 & 100 & 95.2 & 100 & 100 & 95.2 & 100 & 100 \\
\hline
\end{tabular}

Comparisons between sera and eluates from different antigens were made using $\mathrm{c}^{2}$; no statistical difference was observed between them. 
antigens were: L. amazonensis $(\mathrm{r}=0.76)$ and L. chagasi $(\mathrm{r}$ $=0.25)$. The recombinant antigens produced strong correlations between sera and eluate for $\mathrm{rK}-39(\mathrm{r}=0.88)$ and $\mathrm{rK}-26(\mathrm{r}=0.63)$.

Test reproducibility - To evaluate the reliability of the tests, 55 (33\%) duplicate samples in sera and 28 (20\%) duplicate samples in eluates for each antigen were analyzed (Table IV). The agreement varied from 0.74-1.0 for the different antigens. The lowest agreement was observed with ELISA performed with L. chagasi in sera $($ Kappa $=0.74)$ and eluates $($ Kappa $=0.63)$. Highest agreement was detected for r-K39 antigens in both sera (Kappa $=0.81)$ and eluates $($ Kappa $=1.0)$.

\section{DISCUSSION}

Among the 115 dogs IFAT-positive at titers of 1:40, $106(92.2 \%)$ were positive in parasitological exams and were considered to be truly positive, while 25 IFAT-negative, clinically healthy animals were considered to be truly negative. Sensitivities were similar between crude and recombinant antigens and remarkably high for both sera and eluates (97-100\%). Specificity of sera and eluates exceeded $96 \%$ for all antigens except $L$. chagasi in eluate, for which the value was $88 \%$. Concordances between the tests were higher either for sera or eluates $(\mathrm{J}=0.95-1.00)$ except for $L$. chagasi antigen in eluates $(\mathrm{J}=0.88)$.

Similar sensitivity and specificity values in ELISA tests for CVL diagnosis were found by Mancianti et al. (1995), who reported higher sensitivity $(99.5 \%)$ and specificity $(97.1 \%)$ with L. infantum antigen. However, Ashford et al.
TABLE IV

Reproducibility of ELISA performed with crude and recombinants antigens $\mathrm{rK}-39$ and $\mathrm{rK}-26$ in sera and eluates to diagnose canine visceral leishmaniasis

\begin{tabular}{lll}
\hline Antigens & $\begin{array}{l}\text { Serum duplicates } \\
\text { Kappa }(95 \% \text { CI. })\end{array}$ & $\begin{array}{l}\text { Eluate duplicates } \\
\text { Kappa }(95 \% \text { CI })\end{array}$ \\
\hline L. amazonensis & $0.76(0,6-0.95)$ & $0.84(0.53-1.00)$ \\
L. chagasi & $0.74(0.54-0.95)$ & $0.63(0.15-1.00)$ \\
rK-39 & $0.81(0.63-0,99)$ & $1.00(1.00-1.00)$ \\
rK-26 & $0.74(0.54-0.95)$ & $0.84(0.53-1.00)$ \\
\hline
\end{tabular}

CI: confidence intervals; L.: Leishmania

(1993) found sensitivity to be lower than $88 \%$ when they used $L$. chagasi antigen in FAST-ELISA performed with sera.

Sensitivity and specificity of ELISA is greatly influenced by the antigen used to perform the tests (Singh \& Sivakumar 2003). Although the L. chagasi antigen is species-specific, in the present study its performance was slightly inferior to L. amazonensis in ELISA carried out with eluates. Crude antigens are traditionally derived from promastigotes cultivated in vitro and consist of a repertory of somatic antigens and several surface components that vary according to parasite species. The different species and strains that have been used in crude antigens may therefore limit standardization of tests and reproducibility of results (Hommel et al. 1978, Mohammed et al. 1986, Burns et al. 1993).

\section{TABLE III}

Comparison between sera and eluates used in ELISA with crude and the recombinant antigens rK-39 and rK-26 to diagnose canine visceral leishmaniasis

\begin{tabular}{|c|c|c|c|c|c|}
\hline \multicolumn{5}{|c|}{ Sera - L. amazonensis } & \multirow[t]{2}{*}{ Kappa $(95 \%$ CI) } \\
\hline & & Positive (\%) & Negative (\%) & Total & \\
\hline \multirow{5}{*}{$\begin{array}{l}\text { Eluate } \\
\text { L. amazonensis } \\
\text { Total }\end{array}$} & Positive & $114(100)$ & $2(7.7)$ & 116 & $0.95(0.88-1.00)$ \\
\hline & Negative & $0(0)$ & $24(92.3)$ & 24 & \\
\hline & & 114 & 26 & 140 & \\
\hline & & Sera - L. chagasi & & & Kappa $(95 \%$ CI $)$ \\
\hline & & Positive & Negative (\%) & Total & \\
\hline \multirow{5}{*}{$\begin{array}{l}\text { Eluate } \\
\text { L. chagasi } \\
\text { Total }\end{array}$} & Positive & $112(100)$ & $6(21.4)$ & 118 & $0.85(0.74-0.97)$ \\
\hline & Negative & $0(0)$ & $22(78.6)$ & 22 & \\
\hline & & 112 & 28 & 140 & \\
\hline & & Sera - rK-39 & & & Kappa $(95 \%$ CI) \\
\hline & & Positive (\%) & Negative $(\%)$ & Total & \\
\hline \multirow{5}{*}{$\begin{array}{l}\text { Eluate } \\
\text { rK-39 } \\
\text { Total }\end{array}$} & Positive & $109(99.1)$ & $0(0)$ & 109 & $0.97(0.94-1.00)$ \\
\hline & Negative & $1(0.9)$ & 30 (100) & 31 & \\
\hline & & 110 & 30 & 140 & \\
\hline & & Sera - rK-26 & & & Kappa $(95 \%$ CI $)$ \\
\hline & & Positive $(\%)$ & Negative (\%) & Total & \\
\hline Eluate & Positive & $112(99.1)$ & $2(7.4)$ & 114 & $0.93(0.85-1.00)$ \\
\hline rK-26 & Negative & $1(0.9)$ & $25(92.6)$ & 26 & \\
\hline Total & & 113 & 27 & 140 & \\
\hline
\end{tabular}

CI: confidence intervals; L.: Leishmania 
Several purified and recombinants have recently been developed and tested, of which rK-39 antigen (Badaró et al. 1996) is highly sensitive and predictive of the onset of disease manifestation in human VL patients. Badaró et al. (1996) and Scalone et al. (2002) found high sensitivity (98\%) and specificity (99\%) for CVL. However, there is some dispute about the predictive onset of the disease in CVL. Scalone et al. (2002), showed that rK-39 antigen did not predict the onset of disease manifestation while Rhalem et al. (1999) found that asymptomatic dogs were negative for rk-39 antigen. Scalone et al. (2002), considered the efficacy of rK-39 in detecting asymptomatic cases to be markedly different between CVL and human VL.

In our study, crude and recombinant antigens detected the anti-leishmanial antibodies of most asymptomatic and oligoasymptomatic dogs when ELISA was performed with sera. For asymptomatic dogs the highest success rate was observed for L. amazonensis antigen (100\%), followed by L. chagasi and rK-26 antigens (both 98\%). The lowest proportion was observed for rK-39 in eluate (93.7\%). With respect to oligoasymptomatic dogs the proportions were 97.8\% for L. amazonensis and L. chagasi and $95.6 \%$ for rK-26 and rK-39. The results obtained in ELISA with eluates for different antigens were similar to those observed in tests performed in sera. The proportion detected by $\mathrm{rK}$ 39 was similar to that found by Scalone et al. (2002) when they assayed asymptomatic dogs $(92.4 \%)$.

Although both crude antigens (L. amazonensis and $L$. chagasi) showed high sensitivity, they presented crossreactivity with other microorganisms as $T$. cruzi, D. reconditum, and $B$. canis. There are two primary drawbacks to tests performed with crude antigens, i.e., crossreactivity and the inability to discriminate between past and current infections. The recombinant antigens rK-39 and rK-26 performed similarly whether in sera or eluate. They showed high sensitivity but no cross-reactivity with other microorganisms. High specificities of recombinant antigens have also been reported by other authors (Badaró et al. 1996, Scalone et al. 2002).

High concordances were observed between sera and eluates performed with different antigens (Kappa $=0.93$ 0.97). The lowest concordance was observed in L. chagasi antigen (Kappa $=0.88)$. According to Guimarães (1983), errors in conducting tests with filter papers could occur for two possible reasonss : difficulties in precisely estimating eluate dilutions and denaturing of antibodies during filter paper storage at high environmental temperature and relative humidity. The good concordances observed in our study with filter paper are most likely: (1) homogeneity of the blood spread on absorbent filter paper; (2) storage at $-20^{\circ} \mathrm{C}$ and use of silica gel to control humidity; (3) elution of filter papers in casein-PBS on the same day that the tests were carried out.

The evaluation of test reproducibility revealed a good and regular agreement for ELISA in the duplication of eluates (Kappa $=0.63-1.00)$. Eluates of blood dried on filter paper are commonly used in laboratory tests and the validity of this technique has been confirmed for the diagnosis of leishmaniasis (Coutinho et al. 1985, Gomes et al. 2001) and for other infections such as toxoplasmosis and Chagas disease (Chiari et al. 1987, Machado-Coelho et al. 1995).
It is also important to note improvements in the leishmaniasis control program during recent decades in Brazil. The number of dog samples collected increased from 526 to 1,353,812 between 1980 and 1996 (Vieira \& Coelho 1998). Collecting blood on filter paper makes collection, transport and storage of samples easier for local health services (Guimarães 1983).

The use of only one antigen to perform both condition screening and confirmatory tests could increase the proportion of false-positive results, particularly in cases of low prevalence (Gart \& Buck 1966, Costa \& Vieira 2001). One important point that merits consideration is the need to standardize antigens with respect to source and purity in control programs, in order to improve the reproducibility of results in different regions of Brazil.

In summary, the results of this investigation showed that ELISA using crude and recombinant antigens gave results to similar degrees of sensitivity and specificity in identifying different clinical phases of CVL. High concordance among sera and eluates confirm that filter paper could be used to collect blood in canine surveys to identify $L$. chagasi infection. Use of recombinant antigens did not markedly improve results compared with use of crude antigen in dogs identified as being positive. However, the main limitation of crude antigens is their cross-reactivity with other diseases that often occur in VL-endemic areas. The association of crude and recombinant antigens is a strategy that could be used in control programs. This could involve an initial screening using ELISA with crude antigen in eluate from blood collected on filter paper, followed by a confirmatory test using a recombinant antigen also in eluate. However recombinant antigens would need to be widely available. Recombinant antigens could also improve differential diagnosis in clinical veterinary medicine.

\section{ACKNOWLEDGEMENTS}

To Fundação Nacional de Saúde, Minas Gerais, and Dr Marília Rocha, Centro de Controle de Zoonoses de Montes Claros, Minas Gerais for cooperation and logistical support. To Heska Corporation, US for providing the recombinants antigens rK-39 and rK-26 and Dr Terezinha Bahia and Dr Gilberto Fontes for providing the serum of dogs infected with other pathogens. The Conselho Nacional de Desenvolvimento Cientifico e Tecnológico sponsored EY Rosario scholarships (Master Degree - Programa de Pós-Graduação em Parasitologia, Universidade Federal de Minas Gerais).

\section{REFERENCES}

Arias JR, Monteiro PS, Zicker F 1996. The reemergence of visceral leishmaniasis in Brazil. Emerg Infect Dis 2: 145146.

Ashford D, Badaró R, Eulálio C, Freire M, Miranda C, Zalis MG, David JR 1993. Studies on the control of visceral leishmanisis: validation of the falcon assay screening testenzyme-linked immunosorbent assay (FAST-ELISA) for field diagnosis of canine visceral leishmaniasis. Am Soc Trop Med Hyg 48: 1-8.

Badaró R, Benson D, Eulálio MC, Freire M, Cunha S, Netto EM, Pedral SD, Madureira C, Burns J.M, Houghton R.L, David JR, Reed SG 1996. rK-39: a cloned antigen of Leishma- 
nia chagasi that predicts active visceral leishmaniasis. $J$ Infect Dis 173: 758-761.

Bhatia A, Daiffalla NS, Jen S, Badaró R, Reed SG, Skeiky YAW 1999. Cloning, characterization and serological evaluation of K39 and K26: two related hydrophilic antigens of Leishmania chagasi. Mol Biochem Parasitol 102: 249-261.

Braga MDM, Coelho ICB, Pompeu ML, Evans TG, MacAullife IT, Teixeira MJ, Lima JWO 1998. Controle do calazar canino: comparação dos resultados de um programa de eliminação rápida de cães sororreagentes por ensaio imunoenzimático com outro de eliminação tardia de cães sororreagentes por teste de imunofluorescência indireta de eluato de papel filtro. Rev Soc Bras Med Trop 31: 419-424.

Braz RF, Nascimento ET, Martins DR, Wilson ME, Pearson RD, Reed SG, Jeronimo SM 2002. The sensivity and specificity of Leishmania chagasi recombinant K39 antigen in the diagnosis of American visceral leishmaniasis and in differentiating active from subclinical infection. Am J Trop Med Hyg 67: 344-348.

Burns JM, Shreffer WG, Benson DR, Ghalib HW, Badaró R, Reed SG 1993. Molecular characterization of a kinesinrelated antigen of Leishmania chagasi that detects specific antibody in African and American visceral leishmaniasis. Proc Natl Acad Sci USA 90: 775-779.

Carvalho SF, Lemos EM, Corey R, Dietze R 2003. Performance of recombinant K39 antigen in the diagnosis of Brazilian visceral leishmaniasis. Am J Trop Med Hyg 68: 321324.

Chiari CA, Antunes CMF, Lima JD 1987. Utilização do eluato de sangue dessecado em papel filtro no diagnóstico sorológico da toxoplasmose caprina. Rev Bras Med Vet Zootec 39: 471-483.

Costa CHN, Vieira JBF 2001. Changes in the control program of visceral leishmaniasis in Brazil. Rev Soc Bras Med Trop 34: 223-228.

Coutinho SG, Nunes MP, Marzochi MCA, Tramontano N 1985. A survey for American cutaneous and visceral leishmaniasis among 1.342 dogs from areas in Rio de Janeiro (Brazil) where the human diseases occur. Mem Inst Oswaldo Cruz 80: 17-22.

Deane L, Deane M 1962. Visceral leishmaniasis in Brazil. Geographic distribution and transmission. Rev Inst Med Trop São Paulo 4: 149-212.

Evans TG, Vasconcelos IAB, Lima JW, Teixeira JM, McAullife IT, Lopes UG, Pearson RD, Vasconcelos AW 1990. Canine visceral leishmaniasis in northeast Brazil: assessment of serodiagnosis methods. Am J Trop Med Hyg 42: 118-123.

França-Silva JC, Costa RT, Siqueira AM, Machado-Coelho GLL, Costa CA, Mayrink W, Vieira EP, Costa J, Genaro O, Nascimento E 2002. Epidemiology of canine visceral leishmaniosis in the endemic area of Montes Claros municipality, Minas Gerais state, Brazil. Vet Parasitol 2474: 1-13.

Gart JJ, Buck AA 1966. Comparison of a screening test and a reference test in epidemidemiologic studies. II. A probabilistic model for the comparison of diagnostic tests. Am J Epidemiol 83: 593-602.

Gomes HR, Rodrigues MS, Silva MP, Nascimento EG, Moreira ED, Pontes-de-Carvalho LC, Santos WLC 2001. Com- paração entre ELISA de soro e de eluato de sangue para o imunodiagnóstico da leishmaniose visceral canina (LVC). Rev Soc Bras Med Trop 34(Suppl. I): 197.

Guimarães MCS 1983. Inquéritos soroepidemiológicos. Coleta, transporte e armazenamento de amostras. Rev Inst Med Trop São Paulo 25: 93-96.

Hommel M, Peters W, Ranque J, Quilici M, Lanotte G 1978. The micro-ELISA technique in the serodiagnosis of visceral leishmaniasis. Ann Trop Med Parasitol 72: 213-218.

Lanotte G, Rioux JA, Vollhardt Y 1979. Ecologie des leishmanioses dans le sud de la France. Les formes evolutives de la leishmaniose canine Ann Parasitol Hum Comp 54: 277-295

Machado-Coelho GLL, Vitor RWA, Chiari CA, Antunes CMF 1995. Validity of serological for American trypanosomiasis with eluates from filter paper. Mem Inst Oswaldo Cruz 90: 59-64.

Mancianti F, Gramiccia M, Gradoni L, Pieri S 1988. Studies on canine leishmaniasis control. 1. Evolution of infection of different clinical forms of canine leishmaniasis following antimonial treatment. Trans $R$ Soc Trop Med Hyg 82: 566567.

Mancianti F, Falcone ML, Giannelli C, Poli A 1995. Comparison between an enzyme-linked immunosorbent assay using a detergent-soluble Leishmania infantum antigen and indirect immunofluorescence for the diagnosis of canine leishmaniasis. Vet Parasitol 59: 13-21.

Mancianti F, Pedonese F, Poli A 1996. Evaluation of dot enzyme-linked immunosorbent assay (dot-ELISA) for the serodiagnosis of canine leishmaniosis as compared with indirect immunofluorescence assay. Vet Parasitol 65: 1-9.

Marzochi MCA, Coutinho SG, Souza WJS, Toledo LM, Grimald Jr. G, Momen H, Pacheco RS, Sabrosa PC, Souza MA, Rangel Jr. FB, Tramontano N 1985. Canine visceral leishmaniasis in Rio de Janeiro, Brazil. Clinical, parasitological, therapeutical and epidemiological findings (1977-1983). Mem Inst Oswaldo Cruz 80: 349-357.

Mohammed EAER, Wright EP, Rahman AMB, Kolk A, Laarman JJ, Pondman KW 1986. Serodiagnosis of sudanese visceral and mucosal leishmaniasis: comparison of ELISA, immunofluorescence and indirect haemagglutination. Trans $R$ Soc Med Hyg 80: 271-274.

Molina R, Amela C, Nieto J, San-Andres M, Gonzalez F, Castillo JA, Lucientes J, Alvar J 1994. Infectivity of dogs naturally infected with Leishmania infantum to colonized Phlebotomus perniciosus. Trans R Soc Trop Med Hyg 88: 491-493.

Nunes MP, Jackson JM, Carvalho RW, Furtado NJ, Coutinho SG 1991. Serological survey for canine cutaneous and visceral leishmaniosis in area for transmission in Rio de Janeiro where prophylactic measures had been adapted. Mem Inst Oswaldo Cruz 86: 411-417.

Paranhos-Silva M, Freitas LAR, Santos WC, Grimaldi Jr G, Pontes-de-Carvalho LC, Oliveira-dos-Santos AJ 1996. A cross-sectional serodiagnosis survey of canine leishmaniasis due to Leishmania chagasi. Am J Med Hyg 55: 39-44.

Pozio E, Gradoni S, Bettini S, Gramicia M 1981. Leishmaniasis in Tuscany (Italy): VI. Canine leishmaniasis in the focus of Monte Argentario (Grosseto). Acta Trop 38: 383-393.

Rhalem A, Sahibi H, Guessous-Idrissi N, Lasri S, Natami A, 
Riyard M, Berrag B 1999. Immune response against Leishmania antigens in dogs naturally and experimentally infected with Leishmania infantum. Vet Parasitol 81: 173184.

Roffi J, Dedet JP, Desjeux P, Garré MT 1980. Detection of circulating antibodies in cutaneous leishmaniasis by enzymelinked immunosorbent assay (ELISA). Am J Trop Med Hyg 29: 183-189.

Scalone A, De Luna R, Oliva G, Baldi L, Satta G, Vesco G, Mignone W, Turilli C, Mondesire RR, Simpson D, Donoghue AR, Frank GR, Gradoni L 2002. Evaluation of
Leishmania recombinant $\mathrm{K} 39$ antigen as a diagnostic marker for canine leishmaniasis and validation of a standardized enzyme-linked immunosorbent assay. Vet Parasitol 104: 275-285.

Singh S, Sivakumar R 2003. Recent advances in the diagnosis of leishmaniasis. J Postgrad Med 49: 55-60.

Szklo M, Nieto FJ 2000. Epidemiology: Beyond the Basis. Aspen Publishers, Inc., Gaithersburg, 495 pp.

Vieira JBF, Coelho GE 1998. Leishmaniose visceral ou calazar: aspectos epidemiológicos e de controle. Rev Soc Bras Med Trop 31 (Supl. II): 85-92. 
